prise a general chapter on the types of mechanisms which may be involved and a series of "case studies" of individual enzymes which occupy much of the latter half of the book. As well as the obligatory accounts of chymotrypsin and lysozyme the mechanisms of carboxypeptidase, some oxidoreductases and the fructose diphosphate aldolases are discussed. The experimental evidence and the proposed mechanisms are clearly and fairly discussed and the authors are careful to point out any inconsistencies between the mechanisms and the experimental observations.

Despite the lack of depth in many of the earlier chapters, the authors' clear and enthusiastic approach to the topics covered results in a stimulating work which should encourage the reader to delve more deeply with the brief but carefully selected references provided.

K. F. Tipton

\section{Hybrid Cells}

Hybridization of Somatic Cells. By Boris Ephrussi. Pp. 175. (Princeton University Press: New Jersey, 1972.) $£ 2.50$.

Those who wish to read about cell hybridisation can now read books by Harris and by Ephrussi based on lectures given at Harvard and Princeton respectively. Ephrussi goes to some lengths to claim precedence for Barski over Watkins and Harris, a precedence of five years; but there is some difference in hybridity between the mousemouse hybrid of Paris and the manmouse hybrid of Oxford; and, although this was more recent, it was certainly more hybrid.

Both books are well produced, and, if the space taken up by Ephrussi in claiming the priority of his work is excluded, are of similar length. Ephrussi's, which is two years later, has the advantage of being able to quote and evaluate more recent work, but there is little, apart from malignancy, which is not also covered by Harris.

Malignancy is interpreted in terms of a failure of established differentiation, and the differentiated cell is defined as one which has "luxury" activities as well as "housekeeping" activities, to use Ephrussi's polarising terminology. Hybrids between malignant and nonmalignant cells were studied, but, using mice and pre-banding cytological techniques, it was difficult to interpret the nature of the inactivation of some malignant cells through hybridisation, and the decisive observation by which sins of omission could be distinguished from those of commission was not possible.

Those who have already read Harris's book may find the contrast interesting: those who have not should start with the earlier book.

J. H. EDWARDS

\section{Genetics of Oenothera}

Oenothera: Cytogenetics and Evolution. By R. E. Cleland. Pp. $x+370$. (Academic: New York and London, December 1972.) $£ 7$.

Although Ralph Cleland began his research with significant studies of red algae, his life work was devoted to the evolutionary problems presented by Oenothera biennis. This was begun well before he visited Hugo de Vries in Lunteren in 1927-28. De Vries's work seems to have influenced Cleland much more at first than did that of Renner, whose seminal work was published in 1917. The cytogenetics of Oenothera has faded from the view of modern genetics, but it still has an immense importance in the theory of evolution and population structure. It is not impossible that it is on the verge of a significant revival. The permanently heterozygous systems developed in Oenothera have been regarded as blind endings in evolution. Nevertheless, recent work of Levin, Howland and Steiner has shown that Oenothera biennis, the ultimate in permanent heterozygotes maintained by complex interchanges, displays a surprisingly high degree of diversity in cryptic genetic variation as demonstrated by studies of its allozymes. The fitness for particular conditions possessed by current populations has been achieved, it would seem, at the possible expense of future wellbeing of the plants. The Oenotheras with extreme interchange heterozygosity have seemed to many of us to have run into an evolutionary blind alley. But perhaps there is an escape, for some of the genome, especially that at the ends of the chromosomes where chiasmata are concentrated, is capable of fairly free recombination. There seem to be potent possibilities for future evolution, other than the infrequent outcrosses between races which Cleland supposes. Evolution may not be slowed.

Oenothera was first important in the promotion of the mutation theory of evolution. Most of the mutants were not changes in genes but changes in chromosome number-polyploidy and aneuploidy principally. While genetic changes of this kind are sometimes important in evolution, they are not the material on which evolution commonly works. Dr Vries's work, described in the first two chapters, contributed much to assessing the place of mutation in evolution.

Cleland's third chapter, also in part I, "Genetical Behaviour of Oenothera", gives an account of Renner's work on Oenothera and his development of the theory of complexes. Like de Vries, Renner was at first, and perhaps predominantly, a physiologist. However, stimulated by Richard Goldschmidt's erroneous explanation of patroclinous inheritance in Oenothera, Renner was led to undertake experiments of his own which showed that the various species were permanent heterozygotes, each generally producing two gametic complexes, each different from the other in a large number of genes. The cytological basis of these peculiarities, with the fourteen chromosomes forming rings at meiosis and alternate chromosomes passing together to the same spindle pole at division I, was first demonstrated by Cleland in 1922. The explanation of the cytology, based on Belling's concept of segmental interchange, was fully developed by Darlington in 1929 and 1931. The analysis of the relation between the arrangement of the pairing segments of the complexes in a wide range of species was begun by Emerson and Sturtevant in 1931 and developed with great enthusiasm by Cleland. This work is summarized in part II, and part IV, "Evolutionary Considerations", applies the results to population studies in the widest possible way. There is much here not otherwise published and of great interest to all concerned with the principles of evolution.

The third part of Cleland's book includes accounts of the supernumerary chromosomes found in some races, the genetic analysis of the Renner complexes, position effects, self incompatibility, plastid behaviour and the genetics of certain inconstant characters.

Dr Cleland's book is to be recommended as a source of detailed evolutionary information on the genus and as a summary account of the biological importance of the various historical studies which have contributed to our understanding of Oenothera. It should be read by all concerned with the study of evolution.

D. G. Catcheside

\section{All About Interferon}

Interferons and Interferon Inducers. Edited by N. B. Finter. Pp. $x x+598$. (North-Holland: Amsterdam and London; American Elsevier: New York, 1973.) Dfl. $80 ; \$ 25$.

THIS volume contains information on everything you always wanted to know about interferon. The successor to Interferons published in 1966, this completely revised edition retains the core of contributors but very little indeed from the text of its successful predecessor. It has grown to almost twice the size of the previous edition, mainly as a result of the inclusion of new chapters and extensive subject and reference indexes.

As a possibly unintentional hint at its apostolic nature, the book was written by twelve contributors-all of them well known experts in the field. The relative uniformity in the general outline of individual chapters and the liberal use of cross-references reveal 